\title{
Introduction
}

\section{Encounters: Handling, Placing and Looking at Photographs in Relation to Migration}

\author{
Eva-Maria Troelenberg \\ Department of History and Art History, Utrecht University, Utrecht, \\ The Netherlands \\ e.m.troelenberg@uu.nl \\ Costanza Caraffa \\ Kunsthistorisches Institut in Florenz - Max Planck Institut, Florence, Italy \\ Caraffa@khi.fi.it

\section{Anna Sophia Messner} \\ Department Geschichts- und Kunstwissenschaften, LMU München, Munich, \\ Germany \\ messner_anna@web.de
}

Looking at global migration, we are constantly confronted with the 'excess' and 'noise' of photography. ${ }^{1}$ This is not only the effect of the technology of photography as a recording medium and the sheer abundance of visual material, but also of the contrast or conflict between emic and etic perspectives, between the perspective of the subject and the perspective of the observer. This contrast is evident, for instance, when looking at images circulating on social media, or at press coverage. Contemporary and historical photographs connected to migration are often excessive: sometimes because they are explicitly made to represent suffering and displacement, sometimes precisely because they also contain a noise that escapes the photographer's intentionality. It is exactly

1 Pinney 2003; Poole 2005.

(C) TROELENBERG, CARAFFA AND MESSNER, 2020 | DOI:10.1163/22130624-00801004

This is an open access article distributed under the terms of the CC-BY-NC,4.0 License 1 l, com-4/26/2023 01:21:05PM 
these disturbing moments, however, that constituted a point of departure for the interdisciplinary conference 'Encounters: Handling, Placing and Looking at Photographs in Relation to Migration'.2

In this special issue we present a selection of contributions which take their cue from the conference to provide a perspective on the work done by photographs in historical and contemporary processes and movements of migration. The articles investigate the multi-layered historical, material, technical and visual preconditions and effects of the 'migration and photography complex'3 in diachronic perspective, presenting studies ranging from the nineteenth century to the present.

Migration has been debated both as a historical-empirical reality and as a discursive concept in the wake of post-colonial scholarship. ${ }^{4}$ It involves ideas such as displacement and dislocation, exile and diaspora, trauma and memory, interruption and alienation, diversity and alterity as well as nationalism and transnationalism. ${ }^{5}$ Elizabeth Edwards's definition of photographs as 'raw histories', both 'painful' and 'unprocessed, ${ }^{6}$ can also be applied to migration experiences. Photographs have the potential to hurt us because they often bear the thorns of the colonial world; ${ }^{7}$ but, continues Edwards, photographs are also unprocessed, ambiguous, fleeting and changing in meaning. Recodability, the ability to acquire or suggest new meanings in new contexts, is part of their nature. ${ }^{8}$ It is precisely this rawness and ambiguity that represents an enormous potential, also for photographs taken, handled, collected, exchanged and archived in relation to migration. As Tanya Sheehan recently argued, 'most photographs disseminated by the mainstream media offer a highly circumscribed

2 The conference (https://www.khi.fi.it/de/aktuelles/veranstaltungen/2017/10/encountershandling-placing-looking-photographs.php) was a joint activity of the Photothek of the Kunsthistorisches Institut in Florence and the Max-Planck-Research Group 'Objects in the Contact Zone - The Cross-Cultural Lives of Things' (2011-2018). The conference was held on 12-13 October 2017 at the Kunsthistorisches Institut in Florence - Max-Planck-Institut and at the Villa Romana in Florence. The papers presented at the conference ranged from historical case studies up to the current production of digital pictures taken on smartphones and circulating on social networks.

3 Paraphrasing Hevia 2009. See for a short introduction Schwartz 2005.

4 A number of projects, exhibitions and publications have addressed the connection between migration, image and object circulations and visual studies in recent years. See among others: Stegmann 2004; Durrant and Lord 2007; Grossman and O'Brien 2007; Bal 2011; Mathur 2011; Demos 2013; Dogramaci 2013; Moslund, Petersen and Schramm 2015; Nair and Bloom 2015. Most recently: Dogramaci and Mersmann 2019.

5 For some keywords, see Sheehan 2018.

6 Edwards 2001, 5 .

7 Here we have to recall that the material approach in photography studies was developed within British Anthropology with its colonial legacies.

8 Edwards 2001, 5-6. 
view of photography's long and complex relationship to human migration. ... Yet so much more can be pictured and said of the medium's role in the movement of peoples within and across borders. ${ }^{9}$ Sheehan's edited volume as well as a growing number of conferences and initiatives in the last years helped to enlarge the focus from iconic images of migration to a wider and multifaceted photographic production, situated outside current systems of photographic value. The essays collected here are focused not primarily on the representation and documentation of migration in photographic images, but on photographic practices in migration contexts. Furthermore, handling photographs in relation to migration emphasizes the many layers of encounters across time and space that are embodied in the photographs themselves. ${ }^{10}$

In the last decades, photography studies have provided fertile ground for debates about our understanding and critical deconstruction of notions such as indexicality, iconicity, objectivity and evidentiality. Since the 1990s a strand of trans-disciplinary studies has shifted attention back to the materiality of photographic objects, overcoming traditional hierarchies of values based on uniqueness and authoriality. Attention was refocused on the biographies or itineraries - of photographs and their unstable meanings. ${ }^{11}$ The idea of a social biography of photographs, which goes back to Arjun Appaduraj and Igor Kopytoff, ${ }^{12}$ acknowledged their active role in social relations and, thus, their agency. ${ }^{13}$ Both the material turn and the affective turn have contributed significantly to larger debates about the understanding of photographs as threedimensional tactile and visual objects in their own right, as bearers of experience, knowledge and affect, ${ }^{14}$ able to activate and perform relations between human beings. ${ }^{15}$ Thus material practices cannot be separated from social practices. By challenging conventional systems of value based on photographic authoriality and indexicality, the material approach spotlights photographs that act in everyday life. ${ }^{16}$ Popular, everyday photographic practices that are often marginalized in historiography play multiple roles in processes related to migration. Individuals participate in these processes not only as subjects or

\footnotetext{
9 Sheehan 2018, 1.

$10 \quad$ Edwards 2015.

11 Schwartz 1995; Pinney 1997; Edwards 2001; Edwards and Hart 2004.

12 Appadurai 1988; Kopytoff 1988.

13 Gell 1998. See also Latour 2005; Mitchell 2005.

14 Campt 2012; Brown and Phu 2014; Edwards 2015.

15 Olin 2012.

16 For instance, the material qualities of photographs have shaped their adoption in various disciplines like art history or archaeology by affording certain types of use; the anthropological practice of visual repatriation and photo-elicitation allows photographs to act in the material world, producing new opportunities for cross-cultural encounters, for example between anthropologists and the descendants of the photographed people.
} 
consumers, but also as producers of images. These practices and these individuals are at the centre of the discussions pursued in the essays in this special collection.

Migration has very often to do with colonial structures or the problems posed by their dissolution. In general, material approach and postcolonial thinking are useful to detect asymmetries also in cases that are apparently far from any colonial context. ${ }^{17}$ This critical perspective has made us more receptive to the discomforting elements that may crop up even in what at first sight may seem the most inoffensive photographs. Photography's 'inability to exclude the random, ${ }^{18}$ its inability of being completely subordinated to the total control postulated by postmodern theoreticians, derives from the act and materiality of the photographic inscription, independently of whether it is a chemical inscription on a negative or an electronic one in bytes. It is precisely from this 'excess' of photography that alternative narratives and moments of cross-cultural encounter can move ahead. Yet, sometimes the gazes and gestures of the photographed people 'pierce the surface of the image' 19 and let those individuals 'speak again with a full distinct voice'. ${ }^{20}$ The necessity to expand our scholarly viewpoint and include the perspective of the migrants themselves has become a burning issue in scholarship, not only in anthropology.

In her recent work, ${ }^{21}$ Margaret Olin underlines the responsibility of a personal engagement of the researcher on the field of migration and diaspora: a direct, personal experience of what has been defined by others as thuman rights regime'22 that should not lead us to overlook, on the other side, what Olin in her paper at the conference called an inevitable 'dissonance between academic research, photography, and engagement'. Another possible way in this direction has been recently shown, among others, by Thy Phu. Her inquiry about refugee self-representation and also non-representation starts with a caution about the danger of 'perpetuating an imbalanced visual encounter more concerned with how distant spectators view refugees and less with how refugees view themselves'.23 In our eyes, however, these occurrences should not be reduced to the realm of visuality. Only if we respect photographs in

17 Demos 2004

18 Pinney 2008, 93.

19 Pinney 1997, 62.

$20 \quad$ Schwartz 2012.

21 See some already published contributions on Margaret Olin's blog https://touchingphotographs.com.

22 Donnelly, Jack, "International Human Rights: A Regime Analysis." International Organization 40 (3) (1986), 599-642.

23 Phu 2004. A review article by Yannis Hamilakis, published briefly before our publication was finalized, summarizes important aspects of the current discourse, also in relation to ethical questions which arise between the realms of scholarship, exhibition and migration 
their own materiality and are disposed to listen to them, ${ }^{24}$ the photographs themselves and the persons involved will speak to us, and to each other. Here we think of the subjects controlled and reified in ID pictures, colonial-style photographs as well as in a widespread sort of journalistic coverage, but also of the developers of original creative practices who appropriate photographic technologies for their own purposes.

These shifting agencies may be one of the most telling indicators for the polyvalence and ambiguity of modernity. As T.J. Demos has lined out in his introduction to The Migrant Image, the use of the term 'migration' is more than a mere terminological nuance in the modern and contemporary context. He thus claims to move "away from "exile" with its associations with empires, tragic banishments, and harsh penal sentences, and toward "migrant", a more impartial term with allowances for voluntary movement and self-willed acts of mutability and becoming (or so many would believe)."25 Demos's approach is deeply informed by the now classic premises on migration of both Hannah Arendt and Giorgio Agamben, who consider migration and exile as central and active elements of the modern experience. ${ }^{26}$ In this vein, Demos underlines that refugees can represent the 'vanguard' of their age and culture, ${ }^{27}$ thus attributing the notion of potential and agency to the migrant condition, yet without negating its predicament, contingency and proneness to crisis.

This attention for the potentials of the migrant condition implicitly echoes some contemporary positions in photography studies. Elizabeth Edwards recently suggested replacing 'excess' with 'abundance' of photography, which implies plenitude and potential. ${ }^{28}$ It is not a negation of the rawness and disturbance contained in photographs of migration, but rather an invitation to engage with them. In Margaret Olin's words, 'touching photographs' become 'presences' that act within the world to connect people. ${ }^{29}$ Being receptive to the 'presence' embedded in photographs means 'to excavate the possibility of the experience that someone lived through' when the photographs were taken, ${ }^{30}$ or when they were archived, or restituted, or circulated on the web, in the fluid relationship between the analogue and the digital habitat.

(Hamilakis 2019a). Hamilakis (2019b) touches upon issues related to our approach, but appeared too late to be taken into account for this introduction.

24 Campt 2017.

25 Demos 2013, 3.

26 Arendt 1943; Agamben 2008.

27 Demos 2013, 4. On the relevance of migration as a 'defining feature of modernity' particularly in art history, see also Mercer 2008, quote at 7.

28 Edwards 2015, 237-238.

29 Olin 2012.

30 Edwards 2015, 241. 
The subjective experiences of all the parties involved in the photographic encounter (including artists and activists) were our concern at the conference of 2017 that was a fundamental step of the project "Encounters". This is a joint activity of the Photothek of the Kunsthistorisches Institut in Florence and the Max-Planck-Research Group "Objects in the Contact Zone - The Cross-Cultural Lives of Things". This research group, which officially concluded in 2018, focused on the epistemic and political conditions of objects, artworks and visual practices which travel and migrate across time and space. The work of the research group looked at the role and function of modern visual media and at practices of visual representation in such cross-cultural processes. With its interwoven strands of archival practice and academic research, the Photothek provides a laboratory for the international, cross-disciplinary debate on the role and function of photographs and photographic archives in scholarship and in society. Its commitment for over a decade to the question of photographic materiality is combined with research projects that link the photo archive to social and political issues of our time such as migration. The Photothek and the research group share an interest in photographs as objects acting in transcultural contexts. Both in a historical and in a contemporary perspective, one of the main moments of transcultural encounter is that connected to migration. The title of the project alludes to the (photographic) encounters that can take place especially if we turn our attention away from the more iconic images of migration.

The role of the conference must be explained in this sense, beyond that of a place for the production of knowledge and scholarly exchange: the conference itself provided the frame for encounters not only between scholars, but also with artists, photographers and activists - some of them with migration experience themselves. Fide Dayo, Morteza Khaleghi, Armin Linke, Rob Pinney and Massimo Ricciardo presented their work and took active part in the discussion in Florence. Nevertheless, the methodological and ethical question of how to achieve a dialogue able to be shared with migrant people as active interlocutors and not only to involve them as living legitimization of the activities conducted by academics and artists remains open. We are aware of this challenge, although we cannot propose any universal solution: there is no format that can solve the dilemma by automatically avoiding any form of instrumentalisation. At the end, only the personal, respectful contact between individuals can help bridging communication gaps, as it was the case with Morteza Khaleghi who through his presentation "Born Immigrant" generously allowed us to accompany him in a photographic journey on his migration itineraries from Afghanistan, to Iran, to Italy through the Balkan route. Preparing and curating together with Massimo Ricciardo his installation "Objects of Migration, Photo-Objects 
of Art History: Encounters in an Archive" was helpful in identifying the issue of taxonomy as the link between an apparently innocent photographic archive such as that of an art-historical research institute and an archive of objects that literally had to do with the life and death of the migrants who brought them on their journey across the Mediterranean: on a conceptual and historical level, taxonomizing works of art or photographs is a parallel phaenomenon to taxonomizing human beings in races, which produces social asymmetries, conflicts, and migration. These exchanges between scholars, artists and activists have been pursued in form of an online-exhibition dedicated to the artistic contributions, which has been published digitally on the website of the Kunsthistorisches Institut in Florence and complements this issue of the Journal. The exhibition shows among others the obsolescence of any distinction between photographic genres such as fine art, documentary, and vernacular photography. ${ }^{31}$

The articles in this special collection analyze the entanglements between photography and migration mainly by means of case studies, combined with methodological and theoretical considerations. Together, they seek to investigate the interrelation between photography and migration in its aesthetic, material, affective, ethical and archival dimensions. The set of case studies we have put together focuses on examples of historical migration from Europe into the United States, and on both historical migration movements and their contemporary continuities in the Middle East. This thematically somewhat dense pattern of essays provides us with a possibility to interrelate and also contrast different methodological approaches and epistemic frameworks when dealing with interrelated experiences of migration, ranging from the canonized to the individual image, from the explicitly political and institutional to the most personal context, from hermeneutic to qualitative analysis.

Leslie Ureña looks at the canonical work of Lewis Hine, particularly at his Ellis Island portrait series of immigrants arriving in the United States. Her approach takes a new angle, expounding the racial categories and the afterlives of these iconic images as they circulated throughout the twentieth century in different contexts. Issam Nassar's interest lies with the agency of an institutionalized archive, namely the photo collection of the United Nations Relief and Works Agency for Palestine Refugees in the Near East (UNRWA). He addresses the levels of space and time, authority and power which are encapsulated in the image-politics of a supranational institution through the closereading of one photograph between its aesthetic and political values. In Sigrid

31 https://www.khi.fi.it/en/aktuelles/ausstellungen/2019-06-encounters.php. A book on the installation by Massimo Ricciardo and the encounters that it produced is in preparation. 
Lien's essay we encounter a 'personal archive' which tells us what photographs reveal and conceal about a Norwegian family's migration to the United States after 1900, and about the colonial entanglement of such migration processes. Lien's literal 'unpacking' of this archive is at the same time a critical statement on historiographic positions on migration and diaspora. Ya'ara Gil-Glazer presents an almost sociological analysis of a college workshop, connecting contemporary identities in Israel and Palestine with historical family albums. This essay illustrates the immediate, hands-on function of personal albums which are handed down between generations for both recognizing and bridging cultural difference and for the activation of new knowledge-making processes. The juxtaposition of the different case studies and approaches shows at the end the lability of any distinction between private and institutional, personal and political: institutional collections preserve the stories of individuals and personal archives change their functions and meanings when incorporated in institutional contexts. A report by Cathrine Bublatzky on a workshop held in November 2018 about '(Un)sighted Archives of Migration' completes the series giving insights in just one of the numerous initiatives that are flourishing all over the world.

The International Journal for History, Culture and Modernity understands 'modernity, first, as the cultural space in which the strands of thought on past, present and future are woven together and, second, as the intellectual tool that enables us to engage and understand this cultural fabric. ${ }^{32}$ It has been argued throughout the twentieth century that migration is a key factor which probes modern concepts of social and political power as well as its tools of negotiation, putting to debate concepts such as nation state and Human Rights alike: ${ }^{33}$ "Inasmuch as the refugee, an apparently marginal figure, unhinges the old trinity of state-nation-territory, it deserves instead to be regarded as the central figure of our political history." ${ }^{34}$ Considering both the technology and cultural technique of photography and the experience of migration as integral to the texture of modernity 'not as a conceptual and rhetorical framework, but as a reflection of a concrete intervention in the life of real individuals, ${ }^{35}$ this collection of essays thus speaks directly to the 'global and experiential aspects' of modernity, ${ }^{36}$ while at the same time connecting to recent theoretical elaborations in the history of photography.

32 van Eijnatten et al. 2013.

33 Demos 2013, 4; see also Arendt 1943.

34 Agamben 2008, 93.

35 Zeynep and Eldem 2015.

36 Van Eijnatten et al., 2013, 3. 


\section{About the Authors}

Eva-Maria Troelenberg (Dr. phil., LMU Munich 2010) was head of the MaxPlanck-Research Group "Objects in the Contact Zone - The Cross-Cultural Lives of Things" at Kunsthistorisches Institut in Florenz - Max-Planck-Institut from 2011-2018. She has taught the history of Islamic art, modern global art history and transcultural museum history at the Universities of Vienna and Heidelberg and as a visiting professor at LMU Munich and University of Zürich, and she was a research fellow at the Munich Centre for Global History. Since 2018 , she is professor for modern and contemporary art history at Utrecht University. Her publications include the monograph "Mshatta in Berlin - Keystones of Islamic Art" (Dortmund 2017) as well as the edited volumes "Images of the Art Museum - Connecting Gaze and Discourse in the History of Museology" (Berlin 2017, with Melania Savino) and "Collecting and Empires" (Turnout New York 2019, with Maia Gahtan).

Costanza Caraffa (MA in architecture, Milan 1992; PhD in art history, Berlin 2003) has been Head of the Photothek at the Kunsthistorisches Institut in Florenz, Max Planck Institute since 2006. In 2009 she initiated the "Photo Archives" open conference series. After London and Florence 2009, New York and Florence 2011, Los Angeles 2016, and Oxford 2017, the conference "Photo Archives VII. The Majority World" took place in Florence in October 2019 (next planned meeting: Chicago 2021). Between 2015 and 2018 she was coordinator of the collaborative project "Photo-Objects - Photographs as (Research) Objects in Archaeology, Ethnology and Art History". She edited among others "Photo Archives and the Photographic Memory of Art History" (Berlin-Munich 2011), "Photo Archives and the Idea of Nation" (Berlin-Boston 2015, with Tiziana Serena) and "Photo-Objects. On the Materiality of Photographs and Photo Archives" (Berlin 2019, with Julia Bärnighausen, Stefanie Klamm, Franka Schneider and Petra Wodtke).

Anna Sophia Messner (M.A. in Art History, LMU Munich 2011) was a doctoral research fellow in the research group "Objects in the Contact Zone - The CrossCultural Lives of Things" at the Kunsthistorisches Institut in Florenz - MaxPlanck-Institut from 2015-2018. She is a scientific staff member and $\mathrm{PhD}$ candidate at the Institute for Art History and the Institute for Jewish History and Culture at LMU Munich and has taught and researched on Jewish art, historiography and culture, visual culture of Israel and Palestine, modern and contemporary art in a global context, history and theory of photography. Her publications include the article "Visual Constructions of Otherness in 
Pre-State Palestine and the early State of Israel. A Female Perspective through the Camera" (Newcastle upon Tyne 2018) and the edited volume "Reading Objects in the Contact Zone" (Heidelberg 2020, with Eva-Maria Troelenberg and Kerstin Schankweiler (forthcoming)).

\section{References}

Agamben, Giorgio. "Beyond Human Rights." Open 15 (2008 [Italian original 1993]), 90-95.

Appadurai, Arjun, ed. The Social Life of Things. Commodities in Cultural Perspective (Cambridge: Cambridge University Press, 1988).

Arendt, Hannah. 'We Refugees.' Menorah Journal 1 (1943), 69-77.

Bal, Mieke. Art and Visibility in Migratory Culture: Conflict, Resistance, and Agency (Amsterdam: Rodopi, 2011).

Brown, Elspeth H., and Thy Phu, eds. Feeling Photography (Durham, London: Duke University Press, 2014).

Campt, Tina. Image Matters: Archive, Photography and the African Diaspora in Europe (Durham: Duke University Press, 2012).

Campt, Tina. Listening to Images (Durham, London: Duke University Press, 2017).

Demos, T.J. "The Visual Politics of Climate Refugees." In Photography and Migration, ed. Tanya Sheehan (Berlin: Haus der Kulturen der Welt, 2004), 162-176.

Demos, T.J., ed. The Migrant Image: The Art and Politics of Documentary during Global Crisis (Durham: Duke University Press, 2013).

Dogramaci, Burcu, ed. Migration und Künstlerische Produktion: Aktuelle Perspektiven (Bielefeld: Transcript Verlag, 2013).

Dogramaci, Burcu, and Birgit Mersmann, eds. Handbook of Art and Global Migration. Theories, Practices, and Challenges (Berlin, Boston: De Gruyter, 2019).

Donnelly, Jack. "International Human Rights: A Regime Analysis." International Organization 40 (3) (1986), 599-642.

Durrant, Sam, and Catherine M. Lord, eds. Essays in Migratory Aesthetics: Cultural Practice between Migration and Art-Making (Amsterdam: Rodopi, 2007).

Edwards, Elizabeth. Raw Histories: Photographs, Anthropology and Museums (Oxford: Berg, 2001).

Edwards, Elizabeth. "Anthropology and Photography: A Long History of Knowledge and Affect." Photographies 8 (3) (2015), 235-252.

Edwards, Elizabeth, and Janice Hart, eds. Photographs, Objects, Histories: On the Materiality of Images (London: Routledge, 2004).

Gell, Alfred. Art and Agency: An Anthropological Theory (Oxford: Clarendon Press, 1998). 
Grossman, Alan, and Áine O'Brien, eds. Projecting Migration: Transcultural Documentary Practice (London: Wallflower Press, 2007).

Hamilakis, Yannis. "Planet of camps: border assemblages and their challenges." Antiquity 93 (371) (2019a), 1371-1377.

Hamilakis, Yannis, ed. The New Nomadic Age. Archaeologies of Forced and Undocumented Migration (Sheffield: Equinox Publishing Ltd, 2019b).

Hevia,James L. “ThePhotographyComplex:ExposingBoxer-EraChina(1900-1901), Making Civilization." In PhotographiesEast:The CameraandIts Histories inEastandSoutheastAsia, ed. Rosalind C.Morris(Durham:DukeUniversity Press, 2009),79-121.

Kopytoff, Igor. "The Cultural Biography of Things: Commoditization as Process." In The Social Life of Things. Commodities in Cultural Perspective, eds. Arjun Appadurai (Cambridge: Cambridge University Press, 1988), 64-91.

Latour, Bruno. Reassembling the Social: An Introduction to Actor-Network-Theory (Oxford: Oxford University Press, 2005).

Mathur, Saloni, ed., The Migrant's Time: Rethinking Art History and Diaspora (New Haven: Yale University Press, 2011).

Mercer, Kobena. “Introduction." In Exiles, Diasporas \& Strangers, ed. Kobena Mercer (London, Cambridge: The MIT Press, 2008), 6-27.

Mitchell, W.J.T. What Do Pictures Want? The Lives and Loves of Images (Chicago: University of Chicago Press, 2005).

Moslund, Sten Pultz, Anne Ring Petersen and Moritz Schramm, eds. The Culture of Migration: Politics, Aesthetics and Histories (London: Taurus, 2015).

Nair, Parvati, and Tendayi Bloom, eds. Migration Across Boundaries: Linking Research to Practice and Experience (Farnham: Ashgate, 2015).

Olin, Margaret. Touching Photographs (Chicago, London: The University of Chicago Press, 2012).

Phu, Thy. "Refugee Photography and the Subject of Human Interest." In Photography and Migration, ed. Tanya Sheehan (Berlin: Haus der Kulturen der Welt, 2004), 135-149.

Pinney, Christopher. Camera Indica: The Social Life of Indian Photographs (London: Reaktion Books, 1997).

Pinney, Christopher. “Introduction." In Photography's Other Histories, eds. Christopher Pinney, and Nicolas Peterson (Durham: Duke University Press, 2003), 1-16.

Pinney, Christopher. The Coming of Photography in India (London: British Library, 2008).

Poole, Deborah. "An Excess of Description: Ethnography, Race, and Visual Technologies." Annual Review of Anthropology 34 (2005), 159-179.

Sheehan, Tanya, ed. Photography and Migration (London, New York: Routledge, 2018). Stegmann, Petra, ed. Migrating Images: Producing, Reading, Transporting, Translating (Berlin: Haus der Kulturen der Welt, 2004). 
Schwartz, Joan M. “We Make Our Tools and Our Tools Make Us': Lessons from Photographs for the Practice, Politics, and Poetics of Diplomatics." Archivaria 40 (1995), 40-74.

Schwartz, Joan M. "Migration and Photography." In The Oxford Companion to the Photograph (Oxford: Oxford University Press, 2005), 410-411.

Schwartz, Joan M. “To speak again with a full distinct voice.' Diplomatics, Archives, and Photographs". In Archivi fotografici: spazi del sapere, luoghi della ricercar, eds. Constanza Caraffa, and Tiziana Serena (Rome: Carocci, 2012), 7-24.

van Eijnatten, Joris, Ed Jonker, Willemijn Ruberg, and Joes Segal. "Shaping the Discourse on Modernity." International Journal for History, Culture and Modernity 1 (1) (2013), 3-20.

Zeynep, Çelik, and Edhem Eldem, eds. Camera Ottomana: Photography and Modernity in the Ottoman Empire, 1840-1914 (Istanbul: Koç University Press, 2015). 